\title{
Co-production as a driver of client satisfaction with public service organizations: an analysis of German day-care centres
}

\author{
Jörg Lindenmeier (D) ${ }^{\mathrm{a}}$, Ann-Kathrin Seemann (D) $^{\mathrm{b}}$, Oto Potluka (D) \\ and Georg von Schnurbein ${ }^{c}$
}

${ }^{a}$ Chair of Public and Nonprofit Management, University of Freiburg, Freiburg, Germany; ${ }^{b}$ Institute of Tourism (ITW), Lucerne School of Business, Lucerne, Switzerland; 'Center for Philanthropy Studies (CEPS), University of Basel, Basel, Switzerland

\begin{abstract}
This paper investigates the effects of co-production on satisfaction with public service organizations (PSOs) in a day-care setting. Based on a survey of parents from Germany, this paper validates the effects of economic, political, and social participation on satisfaction and considers the level of information, person-organization fit, and structural quality as mediating variables. Mediation analysis shows significant and positive indirect effects of political and social co-production on satisfaction. In contrast, economic co-production has no effect on client satisfaction. Based on the findings and the study's limitations, this paper delineates practical implications and avenues for future research.
\end{abstract}

KEYWORDS Co-production; day-care; client satisfaction; public service organisation; public service logic

\section{Introduction}

Public management has undergone significant changes in recent decades. Since the 1980 s at the latest, the new-public-management paradigm was leading and had initiated massive efforts of administrative reform (Alford 2008). At present, there is a broad consensus that the new-public-management philosophy did not keep (all of) its promises (see, e.g., Osborne, Radnor, and Nasi 2013). One important explanation for new public management's failure can be found in a misguided perspective on the processes of service delivery and public-value creation that is fundamentally based on 'product dominant logic'. Specifically, the new-public-management paradigm implicitly views public organizations as places where an industrial production occurs (Osborne and Strokosch 2013).

Contrary to this view, however, public organizations do not produce material goods. Rather, public organizations provide services to meet public needs. Accordingly, a paradigm shift has occurred in the public management research where 'service dominant logic' has gained significance (Osborne, Radnor, and Nasi 2013). A central idea of this approach is that consumers act as 'co-producers' or 'co-creators' of the 
services that they consume (Vargo and Lusch 2008). Thus, the customer value of services is collaboratively created in an interaction between the service provider and the consumers. Therefore, service providers must make a 'service proposition' that fits with customer needs and must design processes of co-production so that the customer value is maximized and the service providers' competitive position in the marketplace is strengthened.

The co-production phenomenon is just as important to public service organizations (PSOs) as it is to for-profit service companies (Alford 2008). However, the strategic implications of the service dominant logic cannot be fully transferred to the public sector (Osborne 2018); in addition to unwilling and coerced clients (e.g., prisoners) and the existence of multiple stakeholder groups with different and sometimes contrary needs and goals, a high level of client loyalty can be regarded as a negative operating result in the context of public service provision (e.g., homeless people that return again and again to a communal shelter). Against this background, the servicedominant-logic concept was adapted to the public sector under the names of 'public service dominant logic' (e.g., Osborne, Radnor, and Nasi 2013) or 'public service logic' (e.g., Osborne 2018). Coming from the public service logic, Osborne et al. (2015) developed a SERVICE framework for the sustainable management of a PSO. One of the SERVICE framework's propositions states that co-production is a driver not only of the effectiveness of public service provision but also of the generation of innovative public service propositions. Likewise, Bryson et al. (2017) attribute a prominent role to the processes of co-production in the so-called strategic-triangle conceptualization.

Although attention to the participation of citizens in the process of public service provision has strongly increased, several authors (see, e.g., the review article of Voorberg, Bekkers, and Tummers 2015) emphasize significant gaps in the research on citizen co-production. The current study aims at closing some of these gaps. First, according to Voorberg, Bekkers, and Tummers (2015), most studies do not define the factual objectives of co-production strategies, as the focus of such studies is more process-oriented. In addition, there are also papers that doubt the commonly assumed positive effects of co-production (e.g., Williams, Kang, and Johnson 2016). The current study develops and validates a model of the effects of co-production on client satisfaction; therefore, it explicitly tries to explain whether co-production has significant positive or negative outcomes. Second, the mechanisms of the of co-production's effects on public-value creation and on different outcome categories have been insufficiently researched (Loeffler and Bovaird 2016; Osborne, Strokosch, and Radnor 2018), and the conditions that lead to these outcomes remain unclear (Nabatchi et al. 2016). To provide more evidence in this regard and consistent with Hartley et al.'s (2017) request to analyse operational co-production procedures that create public value, this study contemplates various forms of co-production. Furthermore, the current paper considers different mediating variables that are interposed in the assumed causal relationship between co-production and client satisfaction. Third, Verschuere, Brandsen, and Pestoff (2012) and Bovaird et al. (2017), among others, criticize that most of the empirical papers on co-production use qualitative research designs and case study designs. To supplement these more qualitative studies, this survey study uses quantitative cross-sectional data from German clients of childcare services to validate the effects of co-production.

This paper considers childcare services as a factual research object, and this type of public service has some peculiarities. First, different from tax-return services, for 
instance, childcare is characterized by a continuing relationship between users and service providers that lasts for months or years. Second, parents have the option concerning whether and what childcare service to use. Therefore, childcare services are usually voluntarily sought, and no coerced or extremely unwilling customers are involved in the service interactions. Third, the direct beneficiaries of childcare services (i.e., children) are not the persons who participate in the citizen co-production activities that this paper examines (i.e., parents). Accordingly, this paper examines a relationship between a PSO and an important stakeholder group (i.e., parents); Smith and Friedman (1994) call this type of relationship an indirect customer-provider relationship.

\section{Outcomes of co-production in PSOs}

As already mentioned, the integration of users in the process of public service delivery is indispensable. Accordingly, PSOs make value propositions that must meet the needs of clients. PSOs then create public value in an interaction with users or other stakeholders based on these value propositions (Osborne 2018). In contrast to the concept of the service-profit chain (see, e.g., Heskett et al. 1994), which is valid for profitoriented enterprises, the primary goal of PSOs is not the optimization of economic value (i.e., firm profit or companies' stock price); rather, they have to provide value to the public. The conceptualization and measurement of public value and, thus, the outcomes of co-production are not trivial. According to Bryson et al. (2017), there is a plethora of public-value definitions, and these definitions are not congruent. Some definitions focus on instrumental issues (i.e., public organizations' effectiveness); other definitions are more process-oriented (e.g., increasing citizen compliance). Moreover, the strengthening of democracy or reinforcing social cohesion by means of coproduction constitute a public value that is a means in itself. Furthermore, due to their multiple stakeholders with different needs, different and competing objectives can be relevant to the same PSO. Third, unlike profit determination, the outcome measurement in a PSO context is not trivial.

Williams, Kang, and Johnson (2016) emphasize the relational aspect of the public-value concept and state that it can be captured by perceptual indicators. Based on this and comparable to Fledderus (2015), this paper's empirical study considers parent satisfaction as the perceptual indicator of the outcome of coproduction in childcare organizations. Consumer satisfaction is a psychological construct that has been intensively researched in the fields of marketing and consumer psychology (see, e.g., Anderson, Fornell, and Lehmann 1994). Consistent with the notion of the disconfirmation/confirmation paradigm, consumer satisfaction is because of a cognitive process in which quality expectations are compared to the perception of actual quality (Churchill and Surprenant 1982). Therefore, client satisfaction should be high when the service quality meets or exceeds parental needs. Furthermore, equity theory and attribution theory also help to explain variations in satisfaction responses (Oliver and DeSarbo 1988). Equity theory links parental satisfaction to a fairness judgement about the inputoutput ratios of persons involved in service transactions. In a childcare setting, the perceptions of a balanced input-output relationship between, for instance, parents and professional staff should result in favourable satisfaction judgements. According to attribution theory, consumer satisfaction is based on causal inferences, and these 


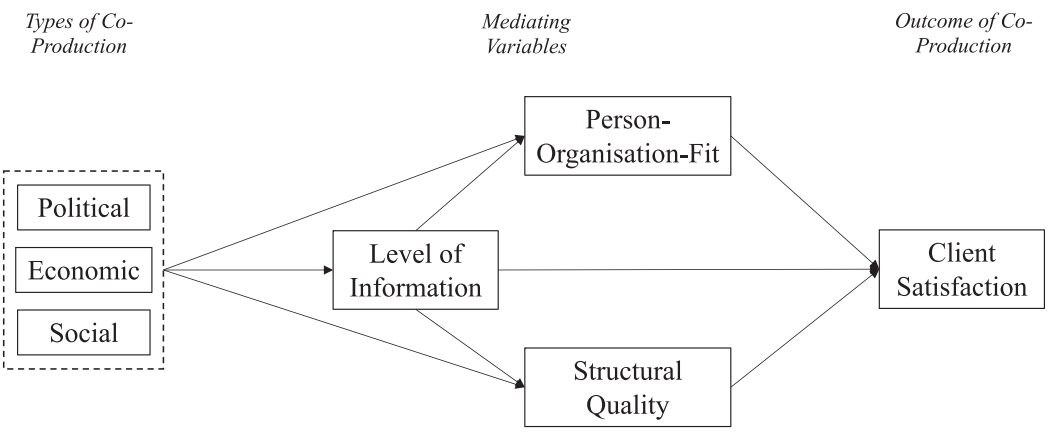

Figure 1. 'Conceptual framework'.

are made in exceptional cases (i.e., distinctly good or bad service experiences). For example, parents may think that a temporary closure of a nursery school due to a flu outbreak could not be controlled by the institution. In the case of this 'noncontrollability' attribution, the dissatisfaction of the parents would not be extremely high. In sum, parental satisfaction appears to be a suitable perceptual indicator that covers a broad range of the facets that constitute the outcomes of co-production. Therefore, the current study considers satisfaction with a PSO as an outcome of client co-production in a childcare setting (see Figure 1).

\section{Co-production in PSOs}

Different actors are involved in the provision of public services, and in particular, collaborations with the third sector and the direct involvement of citizens have become increasingly important. Consistent with this insight, Brandsen and Pestoff (2006) distinguish among three modes of cooperation in public service provision: comanagement, co-governance, and co-production. Poocharoen and Ting (2015) add coconsulting to these three concepts. Co-consulting refers to planning processes in which citizens and professionals are equal partners. Co-management describes constellations in which third-sector organizations produce public services in cooperation with government agencies. Within the framework of co-governance, third-sector organizations participate in the planning and design of public services. These modes of coproduction are of secondary importance because the present study focuses on the phenomenon of citizen co-production, in which citizens as individuals or groups of individuals participate in the production of public services.

According to the idea of the public service dominant logic, the role of the beneficiaries of social services has changed from passive consumers to active stakeholders (Alford 2002). Therefore, according to Brandsen and Honingh 2018, 431) coproduction is defined as 'a relationship between a paid employee of an organization and (groups of) individual citizens that requires a direct and active contribution from these citizens to the work of the organization' (see Cepiku and Giordano 2014 for a review of various other co-production definitions). Bovaird (2007) categorizes different types of relationships between professionals and users. In particular, the typology considers different levels of the participation of users in service delivery and planning (i.e., a continuum from professionals as sole service deliverer to users 
as sole service deliverer). Consistent with Bovaird (2007), Surva, Tõnurist, and Lember (2016) state that co-production encompasses activities of co-design and coimplementation. Voorberg, Bekkers, and Tummers (2015) differentiate between coimplementation, co-design, and citizens as initiators. Confirming these papers, Osborne and Strokosch (2013) distinguish among 'consumer co-production', 'participative co-production', and 'enhanced co-production'. Consumer co-production is located at an operational level of service production and is closely linked to the fact that the production and consumption of services occur simultaneously. According to the authors, PSOs should aim at balancing clients' expectations between public service provision and factual service quality. To the contrary, participative co-production relates to the participation of citizens in the strategic planning and design of the publicservice-provision process (i.e., co-design and citizens as initiators). Participative coproduction aims at strengthening user involvement, while consumer co-production strives for user empowerment. Finally, Osborne and Strokosch (2013) regard enhanced co-production as a combination of co-production at the operational and strategic levels of the public-service-production process. The authors emphasize the user-led innovation of public services as the goal of enhanced co-production.

Nabatchi, Sancino, and Sicilia (2017) provide another typology of the different manifestations of co-production, and the authors' approach considers the level of coproduction (i.e., individual vs. group vs. collective) and the phase of the service cycle (co-commissioning, co-design, co-delivery, and co-assessment) as differentiating factors. Nabatchi, Sancino, and Sicilia (2017) complement other categorization schemes by explicitly considering the prospective and retrospective aspects of co-production (i.e., the ex-ante collection of information about client needs and ex-post assessment of service quality).

\section{Conceptual framework}

The current study builds on Pestoff's (2012) typology of co-production that distinguishes among economic, political, and social co-production. Pestoff developed this typology based on the peculiarities of the Swedish childcare sector, which is similar to the German childcare sector that is the subject of the current study. This study assumes that co-production has a positive effect on client satisfaction. However, the current study hypothesizes that the types of co-production impact satisfaction in an indirect manner. Therefore, in addition to the different forms of co-production as explanatory variables, the conceptual framework includes the level of information available to the parents, person-organization fit, and perceptions of structural quality as mediators. In contrast to a standard mediation model, the present study assumes a more complex relationship between the different types of coproduction, the three mediating variables and client satisfaction: First, this study considers a mediation effect among the three mediators; namely, level of information, perceived structural quality, and perceived person-organization fit. More precisely, this study proposes that structural quality and person-organization fit mediate the effect of level of information on client satisfaction (see hypotheses $\mathrm{H}_{1 \mathrm{a}}$ and $\mathrm{H}_{1 \mathrm{~b}}$ ). Second, this paper then hypothesizes that the perceived level of co-production indirectly affects client satisfaction through the three mediators considered (see mediational hypotheses $\mathrm{H}_{2 \mathrm{a}-\mathrm{c}}$ ). Figure 1 provides an overview of the delineated conceptual framework. 


\section{Mediators of co-production's effect on satisfaction with PSOs}

As mentioned above, the conceptual framework of the current study comprises three mediators; namely, level of information, perceived structural quality, and perceived person-organization fit (see Figure 1). As a first and upstream mediator, the model includes the level of information that is available to the stakeholders (e.g., parents). In line with Dhirathiti's (2018) study, the current study considers the perceived quality of facilities and equipment as a second mediating variable. Based on the service-quality framework of Donabedian (1997) and on Chaebo and Medeiros (2017) structural conditions for effective co-production, the perceived quality of facilities and equipment can be assigned to the subdimension of structural quality. Contrary to process quality, the structural quality of childcare services can be more easily assessed by external parties such as parents. Previous research consistently shows the positive effects of service-quality perceptions on customer satisfaction (e.g., Gok and Sezen 2013).

Acording to Kristof (1996, p. 4 et seq.), person-organization fit as this model's third mediating construct represents 'the compatibility between people and organizations that occurs when: (a) at least one entity provides what the other needs, or (b) they share similar fundamental characteristics, or (c) both'. Person-organization fit has gained great importance in the human resource management research. For instance, Tepeci and Bartlett (2002) show that person-organization fit is as a predictor of employee job satisfaction and other employee-related behavioural intentions (e.g., intentions to leave the organization). Moreover, consistent with Risman, Erickson, and Diefendorff (2016), higher levels of employee-organization fit result in more pronounced work motivations and better work outcomes. The present study takes another perspective and examines consumer-organization fit. Based on a brand-image-transfer rationale, Yaniv and Farkas (2005) show that a strong employee-organization fit can spill over to consumers and can subsequently influence the assessment of the service organizations and their offerings. More importantly, the same authors indicate that a strong consumer-organization fit may also have a positive effect on brand evaluation. The results of the metaanalysis of Kristof Brown, Zimmerman, and Johnson (2005) supports this notion. According to the above definition of Kristof (1996), a strong consumer-organization fit reflects value congruency and the fulfilment of needs. Jaspers and Steen (2019) emphasize that value tensions in PSOs can have a detrimental effect. On the contrary, considering the theory of collective identities, Bagozzi, Bergami Marzocchi, and Morandin (2012) show that close relationships between consumers and organizations that concur in shared knowledge, values, and experiences may result in increased action tendencies that benefit the company. In sum, this study assumes a positive and direct effect of person-organization fit on client satisfaction.

Based on agency theory (Miller 2002), this study assumes a positive effect of the level of information on the perceived quality of facilities and equipment. A better provision of information accords with a mitigation of information asymmetries between clients and PSO. Clients with more information about a PSO's internal structures and procedures have more knowledge about the existing gaps in service and the resulting possibilities for improvement. Based on this broader knowledge, these well-informed clients can better voice their wishes and needs to the social service providers and purposefully influence decision-making processes (Miller 2002). As 
a consequence, the resources available in the PSO are more likely to be allocated to the uses preferred by the clients.

The present study considers the concept of norm crystallization (see Chatman 1989) to explain the effect of the level of information on person-organization fit. Norm crystallization refers to how strongly the members of an organization share universal norms or values. This study assumes that higher levels of information among clients are associated with a stronger intra-organizational dissemination of these values and norms. Furthermore, the level of crystallization represents a determinant of the strength of organizational values, and a high crystallization is consistent with strong intra-organizational ties. Against this background, it is assumed that the perceived person-organization fit increases with the amount of information supplied to the organizations' stakeholders.

Based on the proposed effects of level of information on structural quality and personorganization fit as well as of the effects of structural quality and person-organization fit on client satisfaction, the mediation hypotheses $\mathrm{H}_{1 \mathrm{a}}$ and $\mathrm{H}_{1 \mathrm{~b}}$ read as follows.

$\mathbf{H}_{\mathbf{1 a}}$ : The positive effect of the level of information on satisfaction with a PSO will be mediated by the perceived structural quality.

$\mathbf{H}_{\mathbf{1 b}}$ : The positive effect of the level of information on satisfaction with a PSO will be mediated by the perceived person-organization fit.

\section{Co-production's indirect effect on satisfaction with PSOs}

Economic co-production in childcare facilities manifest itself in the form of cash donations, time donations (e.g., volunteering as cleansing person), or in-kind donations (e.g., books or toys). Furthermore, parents' engagement in direct help in caring for their children is also assigned to economic co-production. Therefore, economic co-production in day-care centres in many cases resembles Bovaird's (2007) notion of the 'user co-delivery of professionally designed services'. According to Pestoff (2009), economic co-production aims at improving service quality and maintaining the common service level (e.g., in times of a high sick leave of professional staff). Economic co-production relates to the operational level of service production and thus has similarities to Osborne and Strokosch's (2013) concept of 'consumer co-production'.

The resource dependency theory may help to explain the effect of economic coproduction on satisfaction. The theory indicates that organizations are to a certain degree dependent on external resources (Wicker and Breuer 2011). Organizations' structure and behaviour are determined by their resources. Users who provide resources to PSOs become economically involved in the provision of public services to ensure both the continued provision of a service and to improve service quality (Pestoff 2009). We hypothesize that an increase in the resources provided by monetary, in-kind, and time donations may lead to better service quality (Prentice 2015), which will subsequently have a positive effect on satisfaction. Hypotheses $\mathrm{H}_{2 \mathrm{a}}$ therefore is

$\mathbf{H}_{2 \mathbf{a}}$ : The positive effect of the level of economic co-production on satisfaction will be mediated by the perceived structural quality. 
Social co-production in childcare facilities relates to festivities (e.g., summer parties or Christmas celebrations), open house days and informational events (see Pestoff 2012). According to Pestoff (2009), parents contribute their time and material goods to these events to achieve 'the social goals of a public service or to promote its social activities' (p. 208). Social co-production cannot be clearly assigned to any of the co-production categories listed above. This can be explained by the fact that social co-production is more associated with bringing people together and disseminating information, ideas, and values than with the actual production of services. In addition, confirming Fledderus, Brandsen, and Honingh (2014), (social) co-production can strengthen the trust among the stakeholders of PSOs. Moreover, since social co-production should therefore promote spreading organizational values, this study assumes that social coproduction reinforces the cohesion between PSOs' internal and external stakeholder groups. This notion is consistent with Chaebo and Medeiros (2017) idea of cognitive conditions for effective co-production. Thus, social co-production should strengthen social ties and result in stronger perceptions of personorganization fit. Therefore, hypotheses $\mathrm{H}_{2 b}$ is

$\mathbf{H}_{\mathbf{2 b}}$ : The level of social co-production has a positive effect, which indirectly affects satisfaction through the mediators' level of information and person-organization fit.

Board meetings with/without the power to decide for parents, suggestion schemes, and possibilities for an informal exchange of ideas and information are appearances of parents' political co-production in childcare organizations (see, Pestoff 2012). Therefore, political co-production is comparable to Bovaird's (2007) concept of a 'traditional professional service provision with user-community consultation on service planning and design issues'. One purpose of political coproduction is to provide users the opportunity to articulate their needs to improve service quality and to generate ideas for service innovations. In addition, political coproduction gives parents the power to make decisions about the way that childcareservice provision is designed. Therefore, the concept of political co-production resembles Osborne and Strokosch (2013) notion of 'participative co-production' on the strategic level.

According to Vidal (2006), co-production leads to a better allocation of resources. Considering this notion, this study hypothesizes that political co-production should result not only in a better representation of clients' preferences due to their involvement in decision-making processes and discussions (Pestoff 2012) but also in an enhanced acceptance of the resulting outcomes (Callahan 2007). Within this context, Osborne and Strokosch (2013) state that co-production can unearth hidden knowledge or latent needs among customers and accordingly, promote innovation processes. These favourable effects of participation in decision making are well-known in the field of medicine, where previous research shows (e.g., Shay and Lafata 2015) that shared decision-making can be associated with higher patient satisfaction.

Because of the communication channel opened by political co-production, information can be better exchanged between the involved parties (Vamstad 2012). In particular, clients who serve as board members receive more and better information about, for instance, daily routines (e.g., children's eating and sleeping hours) or strategic issues (e.g., changes in the range and scope of public services), which reduces 
information asymmetries. Therefore, we assume that stronger political co-production is associated with a higher level of information among client representatives on parent councils and among general clients. According to an agency-theory rationale (Miller 2002), better-informed council members should exert their control function over the service provider's management more effectively and can thus impact decisions more purposefully. A better fulfilment of client needs should also result from political coproduction, and this mechanism should cause higher accountability towards clients and other relevant stakeholders (Van Puyvelde et al. 2012). Therefore, higher levels of political co-production should create better information among parents and subsequently, a better performance of PSOs. Based on this, hypothesis $\mathrm{H}_{2 \mathrm{c}}$ is

$\mathbf{H}_{2 \mathbf{c}}$ : The level of political co-production has a positive effect, which indirectly affects satisfaction through the mediators (i.e., the level of information and structural quality).

\section{Empirical study}

To validate the delineated model, the current study conducts an empirical analysis based on an online survey of parents from Germany. This study applies a partial-least-squares (PLS) structural equating modelling (SEM) methodology. To test the stability of the parameter estimates, this study uses a bootstrapping procedure based on 5,000 bootstrap runs and calculates bias-corrected bootstrapping intervals. According to Hair et al. (2017), a PLS-SEM estimation provides several benefits compared to covariance-based methods, especially when testing complex structural models. For instance, PLS maximizes the explained variances and therefore increases prediction accuracy and does not make strict distributional assumptions.

\section{Setting}

The present study's factual research object is childcare facilities in Germany. In 2017, there were 3,822,837 preschool children supervised in German kindergartens. PSOs from the public sector (32.97\%), the for-profit sector (3.07\%), and the non-profit sector (63.96\%) provided citizens with day-care services. Day-care quality and costs in Germany are mainly regulated on the federal state level. The aspects of quality that are regulated include a minimum teacher-child ratio, a maximum group size, and staff training. Therefore, day-care can vary substantially among German federal states (Schober and Spiess 2015). Kindergarten fees are non-existent or relatively low by international standards. Actual fees are regularly determined depending on the income of the parents. However, costs are covered in large part by municipalities or the state, which means that day-care quality is mostly independent of parents' willingness or ability to pay (Schober and Spiess 2015). Since 2008, parents have had a legal claim to obtain a place in kindergarten for children aged one year. Based on this federal initiative to increase childcare for children younger than three years, significantly higher care rates have been achieved in Germany.

\section{Data gathering procedure}

Parents as indirect clients are the most important stakeholder group of childcare facilities, and we consider parental satisfaction as an indicator of public value 
created by co-production activities. Therefore, the basic population considered in this study is German parents whose children are cared for in day-care facilities. Qualtrics, an online research company, provided access to a national online panel of German citizens. Only the respondents who had a child cared for in a day-care centre were included in the final sample. Moreover, in this study, we only consider the parents who had their children in a public or non-profit kindergarten. Due to their small number, for-profit day-care centres were not taken into account. This procedure yielded a sample of 767 parents. Contrary to the distribution in this study's sample, non-profit kindergartens dominate in Germany. This study corrects for this discrepancy by weighting single cases in the analysis based on the public or non-profit sponsorship of the PSO. Table 1 depicts the distribution of additional characteristics of the childcare facilities.

Table 2 depicts the age and gender characteristics of the interviewed parents in the current study's sample and other demographic characteristics. The current study does not claim representativeness of the sample. First, because of variations in internet usage, national online panels are never representative of the resident population of

Table 1. Distribution of childcare facility characteristics.

\begin{tabular}{|c|c|c|}
\hline \multirow[b]{2}{*}{ Variables } & \multicolumn{2}{|c|}{$\begin{array}{l}\text { Objective measurement sample } \\
\qquad(\mathrm{N}=767)\end{array}$} \\
\hline & $\mathrm{N}$ & $\%$ \\
\hline \multicolumn{3}{|l|}{ Number of nursery groups } \\
\hline 1 group & 27 & 3.52 \\
\hline 2 groups & 83 & 10.82 \\
\hline 3 groups & 150 & 19.56 \\
\hline 4 groups & 192 & 25.03 \\
\hline 5 groups and more & 299 & 38,98 \\
\hline Not specified & 16 & 2.09 \\
\hline \multicolumn{3}{|l|}{ Opening hours } \\
\hline 8:00 pm-12:00 pm (Half-day) & 16 & 2.09 \\
\hline 8:00 pm-2:00 pm (Extended opening hours) & 74 & 9.65 \\
\hline 8:00 pm-5:00 pm (All-day) & 498 & 64.93 \\
\hline Groups with different opening hours & 99 & 12.91 \\
\hline Other opening hours & 79 & 10.30 \\
\hline Not specified & 1 & 0.13 \\
\hline \multicolumn{3}{|c|}{ Special pedagogical concept (e.g., Waldorf, Montessori, bilingual facility or forest kindergarten) } \\
\hline Yes & 141 & 18.38 \\
\hline No & 570 & 74.32 \\
\hline Not specified & 56 & 7.30 \\
\hline \multicolumn{3}{|l|}{ Estimated percentage of children with a migration background } \\
\hline Below $10 \%$ & 322 & 41.98 \\
\hline $10-19 \%$ & 187 & 24.38 \\
\hline $20-29 \%$ & 98 & 12.78 \\
\hline $30 \%$ and more & 119 & 15.51 \\
\hline Not specified & 41 & 5.35 \\
\hline \multicolumn{3}{|l|}{ Cared for children } \\
\hline Only toddlers & 20 & 2.61 \\
\hline Only kindergarten kids & 102 & 13.30 \\
\hline Toddlers and kindergarten kids & 489 & 63.75 \\
\hline Kindergarten kids and school children & 29 & 3.78 \\
\hline Toddlers, kindergarten kids and school children & 127 & 16.56 \\
\hline Inclusive education (i.e., inclusion of children with handicaps) & 354 & 46.15 \\
\hline Childcare facility for children with handicaps only & 14 & 1.83 \\
\hline Parent initiative & 87 & 11.34 \\
\hline Satisfaction with teacher-child ratio & $M=4.52$ & $S D=1.84$ \\
\hline
\end{tabular}


Table 2. Distribution of parent characteristics.

\begin{tabular}{|c|c|c|}
\hline Variables & $\mathrm{N}$ & $\%$ \\
\hline \multicolumn{3}{|l|}{ Age } \\
\hline $18-20$ & 5 & 0.65 \\
\hline $21-25$ & 18 & 2.35 \\
\hline $26-30$ & 111 & 14.47 \\
\hline $31-35$ & 207 & 26.99 \\
\hline $36-40$ & 239 & 31.16 \\
\hline $41-45$ & 128 & 16.69 \\
\hline $46-50$ & 41 & 5.35 \\
\hline 50 and older & 17 & 2.22 \\
\hline Not specified & 1 & 0.13 \\
\hline Male gender & 243 & 31.68 \\
\hline \multicolumn{3}{|l|}{ Marital status } \\
\hline Married & 558 & 72.75 \\
\hline Other marital status & 206 & 26.86 \\
\hline Not specified & 3 & 0.39 \\
\hline Single-parent family & 72 & 9.39 \\
\hline \multicolumn{3}{|l|}{ Volume of employment } \\
\hline Full-time & 374 & 48.76 \\
\hline Part-time (50\% and more) & 166 & 21.64 \\
\hline Part-time (less than $50 \%$ ) & 94 & 12.25 \\
\hline Not employed & 117 & 15.25 \\
\hline Not specified & 16 & 2.09 \\
\hline \multicolumn{3}{|l|}{ Parent council membership } \\
\hline Yes & 175 & 22.82 \\
\hline No & 589 & 76.79 \\
\hline Not specified & 3 & 0.39 \\
\hline \multicolumn{3}{|c|}{ Number of children in the household } \\
\hline 1 & 215 & 28.03 \\
\hline 2 & 384 & 50.07 \\
\hline 3 & 126 & 16.43 \\
\hline 4 and more & 42 & 5.47 \\
\hline \multicolumn{3}{|c|}{ Number of children in the childcare facility } \\
\hline 1 & 521 & 67.93 \\
\hline 2 and more & 246 & 32.07 \\
\hline \multicolumn{3}{|l|}{ School-leaving qualification } \\
\hline No high school diploma & 349 & 45.50 \\
\hline High school diploma & 411 & 53.59 \\
\hline Not specified & 7 & 0.91 \\
\hline \multicolumn{3}{|l|}{ Denomination } \\
\hline Miscellaneous Denominations & 452 & 58.93 \\
\hline Not denominational & 298 & 38.85 \\
\hline Not specified & 17 & 2.22 \\
\hline \multicolumn{3}{|c|}{ Residence (German Federal States) } \\
\hline East Germany and Berlin & 232 & 30.25 \\
\hline West Germany & 534 & 69.62 \\
\hline Not specified & 1 & 0.13 \\
\hline \multicolumn{3}{|c|}{ Inhabitants (Place of Residence) } \\
\hline Below 100.000 & 512 & 67.14 \\
\hline 100.000 to 499.999 & 102 & 13.30 \\
\hline 500.000 and more & 125 & 16.30 \\
\hline Not specified & 28 & 3.65 \\
\hline
\end{tabular}

a specific country. Second, there is no valid information available about the distribution of German parents' demographic and psychographic characteristics that could be used as benchmarks. However, the distribution of school-leaving qualification, respondents' denomination, place of residence, and inhabitants of the place of residence appear to be reasonable. 


\section{Measurement reliability and validity}

This study measures all the model components depicted in Figure 1 based on reflective measurement scales. The co-production scales were based on Pestoff's (2012) conceptualization; 7-point items with 'low degree' and 'high degree' as scale anchors were used. We deleted two items from Pestoff's original economic co-production scale due to problems concerning convergent validity. A direct measurement approach that comprises three 7-point Likert scales was used to measure the person-organization fit. The measurement of the supply of information is based on a self-developed threeitem 7-point Likert scale. The perceived structural quality was measured based on six items. We considered 'very satisfied' and 'not satisfied at all' as the scale's anchors. The overall satisfaction scale was based on Gustafsson, Johnson, and Roos (2005) measurement approach, and we used a continuous measurement scale with numerical values that ranged from 1 to 100 as the scale's anchors. The wording of the question items is depicted in Appendix A.

Table 3 depicts the reliability and validity statistics and the factor loadings. ${ }^{1}$ All factor loadings are significant. The values of the factor reliability and average-varianceextracted (AVE) statistics are above the recommended thresholds. Furthermore, the Fornell-Larcker ratio indicates the discriminant validity of the measurement. A Harman's single factor test and the common-latent-factor method indicate no problems related to common-method bias.

\section{Effects of the covariates}

In addition to the model components depicted in Figure 1, this study also considers covariates, such as age, gender, parents' council membership, migration background, denominational status and satisfaction with the teacher-child ratio. Moreover, all covariates of the 'satisfaction with the teacher-child ratio', which was measured on a metric scale, were operationalized as nominal variables with two or three categories. Appendix B as supplementary information shows the significant effects of the covariates on the model components.

The results indicate a positive effect of parent council membership on personorganization fit $(.07, \mathrm{p}<.05)$ and a positive effect of being in a parent initiative on the perceived level of information $(.06, \mathrm{p}<.01)$, which corresponds to this study's line of reasoning. In addition, the perceived satisfaction with the teacher-child ratio shows a positive effect on all considered variables. Furthermore, a religious non-profit status

Table 3. Descriptive statistics and reliability and validity statistics.

\begin{tabular}{|c|c|c|c|c|c|c|c|c|c|c|c|c|}
\hline & \multicolumn{2}{|c|}{$\begin{array}{l}\text { Descriptive } \\
\text { statistics }\end{array}$} & \multicolumn{3}{|c|}{ Reliability and convergent validity } & \multicolumn{7}{|c|}{$\begin{array}{l}\text { Discriminant validity: Fornell-Larcker } \\
\text { criterion }\end{array}$} \\
\hline & $\begin{array}{l}\text { Mean } \\
\text { value }\end{array}$ & S.D. & $\begin{array}{l}\text { Cronbach's } \\
\text { alpha }\end{array}$ & $\begin{array}{l}\text { Composite } \\
\text { reliability }\end{array}$ & AVE & ECON & INFO & POL & PO & QUAL & SAT & SOC \\
\hline ECON & 2.83 & 1.12 & 0.82 & $\begin{array}{l}0.87 \\
\end{array}$ & 0.52 & 0.72 & & & & & & \\
\hline INFO & 5.15 & 1.31 & 0.91 & 0.94 & 0.84 & 0.3 & 0.92 & & & & & \\
\hline POL & 3.67 & 1.06 & 0.82 & 0.87 & 0.58 & 0.42 & 0.61 & 0.76 & & & & \\
\hline PO & 5.11 & 1.31 & 0.84 & 0.89 & 0.68 & 0.25 & 0.7 & 0.53 & 0.82 & & & \\
\hline QUAL & 5.44 & 1.28 & 0.90 & 0.93 & 0.68 & 0.26 & 0.51 & 0.38 & 0.48 & 0.82 & & \\
\hline SAT & 74.23 & 22.25 & 0.97 & 0.98 & 0.94 & 0.22 & 0.68 & 0.49 & 0.74 & 0.53 & 0.97 & \\
\hline SOC & 3.88 & 0.89 & 0.76 & 0.86 & 0.67 & 0.46 & 0.34 & 0.40 & 0.35 & 0.30 & 0.27 & 0.82 \\
\hline
\end{tabular}


results in lower perceived satisfaction $(-.06, \mathrm{p}<.05)$. The respondents who live in East Germany reveal a higher quality $(.1, \mathrm{p}<.01)$ and higher information level $(.07, \mathrm{p}<.04)$ perceptions. This effect might be due to historical reasons. West German mothers have a history of taking a long maternity leave, while East German mothers pursue a more employment-centred life course. Therefore, West German parents tend to have more conservative attitudes towards day-care use, which results in higher quality expectations (Schober and Spiess 2015). The male respondents reveal a lower perceived person-organization fit $(-.12, \mathrm{p}<.00)$. This effect can be explained by the stillconventional distribution of roles, where women are more involved in early childhood education.

\section{Path analysis and mediation analysis results}

The PLS-SEM results reveal the good explanatory power of the delineated model approach. The adjusted $\mathrm{R}^{2}$ of satisfaction with PSOs is .64. Furthermore, the $\mathrm{R}^{2}$ of the mediators, namely, the structural quality (adjusted $\mathrm{R}^{2}=.35$ ), person-organization fit (adjusted $\mathrm{R}^{2}=.55$ ), and level of information (adjusted $\mathrm{R}^{2}=.44$ ), also indicate a good model fit. Table 4 depicts the values and significance of the path coefficients and their effect sizes $\left(\mathrm{f}^{2}\right)$. The PLS-SEM results reveal no significant direct effects of all three forms of co-production on satisfaction. This finding is consistent with the study's mediation hypotheses $\mathrm{H}_{2 \mathrm{a}-\mathrm{c}}$. The level of information provided to the clients has a significant direct and positive effect on the person-organization fit and perceived structural quality of the facility and equipment. Furthermore, contrary to the mediation hypotheses $\mathrm{H}_{1 \mathrm{a}}$ and $\mathrm{H}_{1 \mathrm{~b}}$, the level of information has a significant direct effect on satisfaction with PSOs.

Table 5 shows the total indirect effects of co-production and the level of information on satisfaction with PSOs. According to hypotheses $\mathrm{H}_{2 \mathrm{~b}}$ and $\mathrm{H}_{2 \mathrm{c}}$, the mediation analysis shows a significant total indirect effect of social co-production and political co-production. However, political co-production has the strongest total indirect effect on satisfaction.

Table 4. Path coefficients (direct effects) and effect sizes".

\begin{tabular}{|c|c|c|c|c|c|c|}
\hline & \multirow[b]{2}{*}{ Path coefficients } & \multirow[b]{2}{*}{ T Statistics } & \multirow[b]{2}{*}{$P$ values } & \multicolumn{2}{|c|}{ Bias-corrected bootstrap interval } & \multirow[b]{2}{*}{$f^{2}$} \\
\hline & & & & $2.5 \%$ & $97.5 \%$ & \\
\hline $\mathrm{ECON} \rightarrow$ INFO & 0.01 & 0.26 & 0.79 & -0.06 & 0.07 & 0.00 \\
\hline $\mathrm{ECON} \rightarrow \mathrm{PO}$ & -0.02 & 0.61 & 0.54 & -0.08 & 0.04 & 0.00 \\
\hline $\mathrm{ECON} \rightarrow$ QUAL & 0.07 & 1.80 & 0.07 & -0.01 & 0.15 & 0.01 \\
\hline ECON $\rightarrow$ SAT & -0.02 & 0.63 & 0.53 & -0.08 & 0.03 & 0.00 \\
\hline $\mathrm{POL} \rightarrow \mathrm{INFO}$ & 0.47 & 13.55 & 0.00 & 0.40 & 0.53 & 0.28 \\
\hline $\mathrm{POL} \rightarrow \mathrm{PO}$ & 0.12 & 3.18 & 0.00 & 0.05 & 0.19 & 0.02 \\
\hline $\mathrm{POL} \rightarrow \mathrm{QUAL}$ & 0.03 & 0.64 & 0.52 & -0.07 & 0.13 & 0.00 \\
\hline $\mathrm{POL} \rightarrow \mathrm{SAT}$ & 0.05 & 1.49 & 0.14 & -0.02 & 0.11 & 0.00 \\
\hline $\mathrm{SOC} \rightarrow$ INFO & 0.09 & 2.64 & 0.01 & 0.02 & 0.15 & 0.01 \\
\hline $\mathrm{SOC} \rightarrow \mathrm{PO}$ & 0.10 & 2.72 & 0.01 & 0.03 & 0.17 & 0.01 \\
\hline $\mathrm{SOC} \rightarrow$ QUAL & 0.11 & 2.54 & 0.01 & 0.02 & 0.19 & 0.01 \\
\hline $\mathrm{SOC} \rightarrow$ SAT & -0.04 & 1.64 & 0.10 & -0.09 & 0.01 & 0.00 \\
\hline INFO $\rightarrow$ PO & 0.53 & 14.19 & 0.00 & 0.46 & 0.61 & 0.35 \\
\hline INFO $\rightarrow$ QUAL & 0.33 & 7.02 & 0.00 & 0.24 & 0.43 & 0.10 \\
\hline INFO $\rightarrow$ SAT & 0.21 & 5.20 & 0.00 & 0.13 & 0.29 & 0.05 \\
\hline $\mathrm{PO} \rightarrow \mathrm{SAT}$ & 0.46 & 10.63 & 0.00 & 0.37 & 0.54 & 0.26 \\
\hline QUAL $\rightarrow$ SAT & 0.13 & 3.73 & 0.00 & 0.07 & 0.21 & 0.03 \\
\hline
\end{tabular}

The table does not report the effects of the covariates. 
Table 5. Total indirect effects of co-production and level of information on satisfaction with PSOs.

\begin{tabular}{lccccc}
\hline & & & \multicolumn{2}{c}{ Bias-corrected bootstrap intervals } \\
\cline { 3 - 6 } & Total indirect effect & T Statistics & P values & $2.5 \%$ & $97.5 \%$ \\
\hline ECON $\rightarrow$ SAT & -0.01 & 0.36 & 0.72 & -0.09 & 0.05 \\
POL $\rightarrow$ SAT & 0.34 & 9.31 & 0.00 & 0.26 & 0.41 \\
SOC $\rightarrow$ SAT & 0.06 & 1.71 & 0.09 & -0.01 & 0.13 \\
INFO $\rightarrow$ SAT & 0.50 & 12.97 & 0.00 & 0.42 & 0.57 \\
\hline
\end{tabular}

Furthermore, contrary to hypothesis $\mathrm{H}_{2 \mathrm{a}}$, the total indirect effect of economic coproduction on satisfaction is not significant. As Table 4 shows, this non-significant total effect is caused by the fact that only one of the direct effects of economic co-production on the mediating variables is significant (i.e., the direct effect on structural-quality perception). Consistent with hypotheses $\mathrm{H}_{1 \mathrm{a}}$ and $\mathrm{H}_{1 \mathrm{~b}}$, the total indirect effect of the level of information on satisfaction is significant. Considering the level of information's significant direct effect, the current study shows that the effect of the information level is only partially mediated by person-organization fit and quality perceptions.

Table 6 reports the values and significance of all possible specific indirect effects. According to the previous mediation results, this more detailed mediation analysis reveals several large indirect effects of political co-production, which is consistent with hypothesis $\mathrm{H}_{2 \mathrm{c}}$. The positive indirect effects of political co-production on personorganization fit and structural quality are very pronounced. In particular, the $\mathrm{POL} \rightarrow \mathrm{INFO} \rightarrow \mathrm{PO} \rightarrow \mathrm{SAT}$ effect is decisive for the explanation of variations in the parents' satisfaction ratings. The specific indirect effects of social co-production are not as pronounced as the specific indirect effects of political co-production. Furthermore, also contrary to hypothesis $\mathrm{H}_{2 \mathrm{a}}$, there are no significant specific indirect

Table 6. Specific indirect effects.

\begin{tabular}{|c|c|c|c|c|}
\hline & \multirow[b]{2}{*}{ Indirect effects } & \multirow[b]{2}{*}{ P-values } & \multicolumn{2}{|c|}{ Bias-corrected bootstrap intervals } \\
\hline & & & $2.5 \%$ & $97.5 \%$ \\
\hline $\mathrm{ECON} \rightarrow \mathrm{INFO} \rightarrow \mathrm{PO}$ & 0.00 & 0.79 & -0.03 & 0.04 \\
\hline $\mathrm{POL} \rightarrow \mathrm{INFO} \rightarrow \mathrm{PO}$ & 0.25 & 0.00 & 0.21 & 0.30 \\
\hline $\mathrm{SOC} \rightarrow \mathrm{INFO} \rightarrow \mathrm{PO}$ & 0.05 & 0.01 & 0.01 & 0.08 \\
\hline $\mathrm{ECON} \rightarrow \mathrm{INFO} \rightarrow$ QUAL & 0.00 & 0.80 & -0.02 & 0.03 \\
\hline $\mathrm{POL} \rightarrow \mathrm{INFO} \rightarrow$ QUAL & 0.16 & 0.00 & 0.11 & 0.21 \\
\hline $\mathrm{SOC} \rightarrow \mathrm{INFO} \rightarrow$ QUAL & 0.03 & 0.01 & 0.01 & 0.06 \\
\hline ECON $\rightarrow$ INFO $\rightarrow$ SAT & 0.00 & 0.80 & -0.01 & 0.02 \\
\hline $\mathrm{POL} \rightarrow \mathrm{INFO} \rightarrow \mathrm{SAT}$ & 0.10 & 0.00 & 0.06 & 0.14 \\
\hline $\mathrm{SOC} \rightarrow \mathrm{INFO} \rightarrow$ SAT & 0.02 & 0.01 & 0.01 & 0.03 \\
\hline $\mathrm{ECON} \rightarrow \mathrm{PO} \rightarrow \mathrm{SAT}$ & -0.01 & 0.54 & -0.04 & 0.02 \\
\hline $\mathrm{ECON} \rightarrow \mathrm{INFO} \rightarrow \mathrm{PO} \rightarrow \mathrm{SAT}$ & 0.00 & 0.79 & -0.01 & 0.02 \\
\hline $\mathrm{POL} \rightarrow \mathrm{INFO} \rightarrow \mathrm{PO} \rightarrow \mathrm{SAT}$ & 0.12 & 0.00 & 0.09 & 0.15 \\
\hline $\mathrm{SOC} \rightarrow \mathrm{INFO} \rightarrow \mathrm{PO} \rightarrow \mathrm{SAT}$ & 0.02 & 0.02 & 0.01 & 0.04 \\
\hline INFO $\rightarrow$ PO $\rightarrow$ SAT & 0.24 & 0.00 & 0.19 & 0.30 \\
\hline $\mathrm{POL} \rightarrow \mathrm{PO} \rightarrow \mathrm{SAT}$ & 0.06 & 0.00 & 0.02 & 0.09 \\
\hline $\mathrm{SOC} \rightarrow \mathrm{PO} \rightarrow \mathrm{SAT}$ & 0.04 & 0.00 & 0.01 & 0.08 \\
\hline $\mathrm{ECON} \rightarrow \mathrm{QUAL} \rightarrow \mathrm{SAT}$ & 0.01 & 0.11 & 0.00 & 0.02 \\
\hline $\mathrm{ECON} \rightarrow \mathrm{INFO} \rightarrow \mathrm{QUAL} \rightarrow \mathrm{SAT}$ & 0.00 & 0.81 & 0.00 & 0.00 \\
\hline $\mathrm{POL} \rightarrow \mathrm{INFO} \rightarrow \mathrm{QUAL} \rightarrow \mathrm{SAT}$ & 0.02 & 0.00 & 0.01 & 0.04 \\
\hline $\mathrm{SOC} \rightarrow \mathrm{INFO} \rightarrow$ QUAL $\rightarrow$ SAT & 0.00 & 0.06 & 0.00 & 0.01 \\
\hline INFO $\rightarrow$ QUAL $\rightarrow$ SAT & 0.05 & 0.00 & 0.02 & 0.08 \\
\hline $\mathrm{POL} \rightarrow \mathrm{QUAL} \rightarrow \mathrm{SAT}$ & 0.00 & 0.54 & -0.01 & 0.02 \\
\hline $\mathrm{SOC} \rightarrow \mathrm{QUAL} \rightarrow \mathrm{SAT}$ & 0.01 & 0.03 & 0.00 & 0.03 \\
\hline
\end{tabular}


effects of economic co-production on satisfaction or the mediators. Finally, according to hypotheses $\mathrm{H}_{1 \mathrm{a}}$ and $\mathrm{H}_{1 \mathrm{~b}}$, the perceived structural quality and person-organization fit mediate the effect of the level of information on satisfaction. Notably, the indirect effect of the level of information via person-organization fit is considerably stronger than the indirect effect of the level of information via perceived quality.

\section{Discussion of the study results}

This study demonstrates that co-production has a significant indirect effect on client satisfaction. The level of information provided to the parents, the perceived personorganization fit and the structural quality all function as mediating variables. Furthermore, the level of information provided to the clients is an essential antecedent of both the perceived person-organization fit and the service quality evaluations. Therefore, consistent with previous research, co-production mitigates the information asymmetry between users and service providers (Vamstad 2012); it also strengthens clients' attachment to the organization (Bagozzi et al. 2012) and perceived structural quality, which, in turn, improves perceived satisfaction (Gok and Sezen 2013).

The considered dimensions of co-production does not have equally strong effects on satisfaction. More precisely, economic co-production does not have a direct or indirect effect on satisfaction. Furthermore, according to the study's assumptions, the level of economic co-production has no significant effect on person-organization fit. Confirming the resource-dependency theory, economic co-production significantly increases the perceived structural quality. However, this direct effect of economic coproduction is quite low. According to Pestoff, Osborne, and Brandsen (2006) and as this study has discussed above, economic co-production is strongly characterized by volunteering. Considering a line of argumentation from Kreutzer and Jäger (2011), the weak effect of economic co-production can be explained by dysfunctional conflicts between volunteers and professional staff. Lavasseur (2018) also addresses these conflicts of interests and resulting struggles between full-time employees and volunteers. In addition, Osborne and Strokosch (2013) indicate that volunteers have experience and skills. However, volunteers can supplement the professional staff only to a limited extent and only in certain areas. That is, as Andreassen, Breit, and Legard (2014) put it, co-production in the form of volunteering has its barriers in the lack of experience and in the dilettantism on the clients' side. Accordingly, a high degree of economic coproduction does not necessarily have to be associated with the positive outcomes of PSO activities. In addition to the positive effects of volunteering on organizational efficiency, Musso, Young, and Thom (2019) emphasize that volunteer management increases administrative complexity, which can also be used as an explanation for the weak effect of co-production. Finally, parents can attribute the need for economic coproduction to the management incompetency in PSOs as well as to insufficient funding. According to attribution theory (see, e.g., Oliver and DeSarbo 1988), such external causal attributions of negative events can result in marked dissatisfaction responses. Therefore, the positive and negative influences of economic co-production on the satisfaction among the parents may have offset one another.

Social co-production has a moderate positive total indirect effect on satisfaction with PSOs. The specific indirect effects reveal that social co-production impacts satisfaction via the person-organization fit and level of information. Therefore, supporting daycare providers by helping at social events increases parents' level of information. Based 
on this insight and according to Chatman's (1989) norm-crystallization rationale, it can be concluded that social co-production contributes to the dissemination of values that are valid throughout the PSOs. These mutual values then contribute to a sense of common bond (i.e., person-organization fit), which is a direct antecedent of satisfaction among the clients of PSOs. Thus, participation in the planning and implementation of social events fosters the shared similarity between a person's self-concept and his or her image of the organization. Nevertheless, the social co-production effect on satisfaction with PSOs is not very pronounced. Furthermore, consistent with Williams and colleagues' (2016) notion, the PLS-SEM analysis (see Table 4) reveals a negative direct effect of social co-production that is almost significant $(\mathrm{p}=.10)$. With more families where both partners work full-time, social co-production in terms of supporting bake sales, Christmas parties, and so on necessitates considerable effort from parents. There might be little understanding of calls for help, and parents may perceive that they do not obtain any additional value for their time invested. Moreover, the social pressure from other parents might be the only reason why parents are involved in social co-production activities, and the 'compulsory' nature of social co-production may result in a negative impact on satisfaction. Therefore, examined from the perspective of equity theory (see, e.g., Oliver and DeSarbo 1988), the modest positive satisfaction responses could be due to the parents' perception of unfair input-output relations.

Political co-production has the strongest total indirect effect on the satisfaction with childcare facilities. The strongest specific indirect effects of political co-production on satisfaction run through the information level and then through either personorganization fit or structural quality on the satisfaction with PSOs. Being involved in decision-making processes, for example, by serving as a board member or by being a member in a parent initiative, results in an increase in the level of information among parents and apparently decreases the unfavourable impact of information asymmetries (Pestoff 2014). In addition, the positive influence via perceived quality can be explain by the notion that political co-production gives clients more control over the planning and delivery of the services that they or their children use (Bovaird 2007; Pestoff 2009). Therefore, the result of this study complies with the previous research that reveals that parental control in the provision of childcare helps to increase the quality of services (Leviten-Reid 2012). Furthermore, by being involved in political co-production, clients may influence the organization in terms of its characteristics, culture and goals, which leads to a better match between the clients' and organizations' values and therefore increases satisfaction.

\section{Limitations, implications, and avenues for future research}

This study's results have to be considered against the backdrop of its limitations. First, the study considers a specific type of social service in one European country; thus, the extent to which the study exhibits external validity is not certain. Second, this survey study considers one information source and measures the model's components by employing one instrument. Thus, common method bias could present a problem. We attempted to address this problem by using different measurement scales and scale anchors. Moreover, the results of the common method bias assessment did not reveal any pronounced problems. Third, this study does not claim representativeness regarding the respondents (i.e., parents) in the sample. Fourth, the validated model represents a consumer psychological model approach of client satisfaction, and we did not control 
for all possible structural variables (e.g., facility size). Fifth, the present study does not formulate hypotheses for every possible direct or indirect effect. Therefore, the present study has to a certain degree an exploratory nature. Finally, the current study explains client satisfaction and thus considers only one public-value indicator.

In particular, the measures of political co-production appear to be instrumental in increasing client satisfaction. Therefore, PSOs could implement structures of political coproduction. Prima facie, the positive mediated effect of social co-production (e.g., joint organization and the holding of open house days or church festivals) on client satisfaction suggests the advantageousness of an increase in social co-production. However, because of only a moderate effect on client satisfaction, managerial decisions concerning social co-production have to be made deliberately. For instance, social service providers should keep in mind that an increase in social co-production might increase clients' performance expectations. According to the confirmation/disconfirmation paradigm of customer satisfaction, non-profit social service providers should either control performance expectations or improve their performance to prevent dissatisfaction among clients. Moreover, the organizations should avoid putting parents under pressure so that they do not feel overly obligated to support the kindergarten by volunteering.

This study opens several avenues for future research. First, additional structural and process variables could be included. For example, future research could consider the different locations of the facilities (urban vs. rural), facility size or educational concepts as explanatory or control variables. Second, future research could focus on intercultural differences or consider other areas of public-service provisions, such as nursing homes, housing assistance or services for disabled people. Third, due to the specific conditions in Germany, the study should be replicated in other countries to ensure external validity. Fourth, based on Bovaird's (2007) classification of professional-user relationships, the current model approach or modified versions of it could be tested in different settings (e.g., user-community co-delivery with professionals, without formal planning and design processes). Fifth, considering a notion of Osborne and Strokosch (2013) among others, future research could analyse how co-production influences the innovation activity of PSOs. Finally, future research could examine parents' initiatives in more detail. These parents' initiatives represent the kindergartens that are founded by parents and have a high degree of parent participation. Such an analysis could provide a more indepth understanding of the drivers, barriers, and outcomes of participatory mechanisms.

\section{Note}

1. In addition, a confirmatory factor analysis reveals a very good global fit of the measurement model with $\chi^{2}=724.61 ; \mathrm{p}<.001 ; \chi 2 / \mathrm{df}=3.06$; CFI $=0.95$, SRMR $=0.05$; RMSEA $=0.05$; PCLOSE $=0.24$.

\section{Disclosure statement}

No potential conflict of interest was reported by the authors.

\section{Notes on contributors}

Jörg Lindenmeier is a full professor of Public and Nonprofit Management at the University of Freiburg, Germany. His research is focused on consumer and prosocial behavior. His research 
addresses ethical consumption, donation and volunteering behavior, and innovation acceptance. Jörg has published articles in the Journal of Business Research, Journal of Macromarketing, Nonprofit and Voluntary Sector Quarterly, Journal of Nonprofit and Public Sector Marketing, Public Management Review, Tourism Management, and Transportation Research, Part A: Policy and Practice among others. Email: joerg.lindenmeier@vwl.uni-freiburg.de

Ann-Kathrin Seemann is a leader of a bachelor programme at the Lucerne University of Applied Sciences and Arts, Switzerland. Her research is focused on consumer behavior in the public and nonprofit context. Her research addresses ethical consumption, decision-making behavior, and non-profit marketing. Ann-Kathrin has published articles in the Journal of Macromarketing, in Health Services Management Research, Housing Studies and the Journal for Public and Nonprofit Services among other publications. Email: ann-kathrin.seemann@vwl.uni-freiburg.de

Oto Potluka is a senior researcher at the Center for Philanthropy Studies (CEPS) at the University of Basel. He graduated at the University of Economics Prague, Faculty of Economics and Public Administration in 1998. Then, he obtained Ph.D. at the Charles University Prague, Faculty of Social Sciences in 2009. His concerns are evaluations of programmes supporting local and regional development, especially programs of the EU Cohesion Policy, including the role of the civil society in development policies. He is a member of several international associations - Regional Studies Association, European Evaluation Society, American Evaluation Association, Swiss Evaluation Society (SEVAL) and Czech Evaluation Society (he was a member of the board of directors for four years).Email: oto.potluka@unibas.ch

Georg von Schnurbein is associate professor at the Faculty of Economics and founding director of the Center for Philanthropy Studies (CEPS) at the University of Basel, Switzerland. His research focuses on nonprofit governance, financial health of nonprofits, and impact assessment. He serves as member of the editorial board of Management \& Leadership and Voluntary Sector Review. Besides, he is member of the international research advisory council of the Satell Institute. Georg von Schnurbein holds a master degree in Business Administration of the University of Fribourg/CH. Besides, he has studied political science at the University of Berne. He is the author of various publications on subjects such as foundation management, governance, and nonprofit management and marketing. Email: georg.vonschnurbein@unibas.ch

\section{ORCID}

Jörg Lindenmeier (D) http://orcid.org/0000-0001-6736-7067

Ann-Kathrin Seemann (ID) http://orcid.org/0000-0001-9011-1561

Oto Potluka (D) http://orcid.org/0000-0002-9558-9473

\section{References}

Alford, J. 2002. "Why Do Public-sector Clients Coproduce? Toward a Contingency Theory." Administration \& Society 34 (1): 32-56. doi:10.1177/0095399702034001004.

Alford, J. 2008. "A Public Management Road Less Travelled: Clients as Co-producers of Public Services." Australian Journal of Public Administration 57 (4): 128-137. doi:10.1111/j.14678500.1998.tb01568.x.

Anderson, E. W., C. Fornell, and D. R. Lehmann. 1994. "Customer Satisfaction, Market Share, and Profitability: Findings from Sweden." Journal of Marketing 58 (3): 53-66. doi:10.2307/ 1252310.

Andreassen, T. A., E. Breit, and S. Legard. 2014. “The Making of 'professional Amateurs'.” Acta Sociologica 57: 325-340. doi:10.1177/0001699314552736.

Bagozzi, R. P., M. Bergami, G. L. Marzocchi, and G. Morandin. 2012. "Customer-Organization Relationships: Development and Test of a Theory of Extended Identities." Journal of Applied Psychology 97 (1): 63-76. doi:10.1037/a0024533.

Bovaird, T. 2007. "Beyond Engagement and Participation: User and Community Coproduction of Public Services.” Public Administration Review 67 (5): 846-860. doi:10.1111/j.1540-6210.2007.00773.x. 
Bovaird, T., S. Flemig, E. Loeffler, and S. P. Osborne. 2017. "Debate: Co-production of Public Services and Outcomes." Public Money \& Management 37 (5): 363-364. doi:10.1080/09540962.2017.1294866.

Brandsen, T., and M. Honingh. 2018. "Definitions of Co-production and Co-creation." In Coproduction and Co-creation: Engaging Citizens in Public Services, edited by T. Brandsen, T. Steen, and B. Verschuere, 10-17. Abingdon: Routledge.

Brandsen, T., and V. Pestoff. 2006. "Co-production, the Third Sector and the Delivery of Public Services: An Introduction.” Public Management Review 8 (4): 493-501. doi:10.1080/ 14719030601022874 .

Bryson, J., A. Sancino, J. Benington, and E. Sørensen. 2017. "Towards a Multi-actor Theory of Public Value Co-creation." Public Management Review 19 (5): 640-654. doi:10.1080/14719037.2016.1192164.

Callahan, K. 2007. "Citizen Participation: Models and Methods." International Journal of Public Administration 30 (11): 1179-1196. doi:10.1080/01900690701225366.

Cepiku, D., and F. Giordano. 2014. "Co-production in Developing Countries: Insights from the Community Health Workers Experience." Public Management Review 16 (3): 317-340. doi:10.1080/14719037.2013.822535.

Chaebo, G., and J. J. Medeiros. 2017. "Conditions for Policy Implementation via Co-production: The Control of Dengue Fever in Brazil." Public Management Review 19 (10): 1381-1398. doi:10.1080/ 14719037.2016.1209231.

Chatman, J. A. 1989. "Improving Interactional Organizational Research: A Model of Person-organization Fit." Academy of Management Review 14 (3): 333-349. doi:10.5465/ amr.1989.4279063.

Churchill, J. G. A., and C. Surprenant. 1982. "An Investigation into the Determinants of Customer Satisfaction.” Journal of Marketing Research 19 (4): 491-504. doi:10.2307/3151722.

Dhirathiti, N. S. 2018. "Co-production and the Provision of Lifelong Learning Policy for Elderly People in Thailand." Public Management Review 21 (7): 1011-1028. doi:10.1080/ 14719037.2018.1540723.

Donabedian, A. 1997. “The Quality of Care." Archives of Pathology \& Laboratory Medicine 121: 11.

Fledderus, J. 2015. "Does User Co-production of Public Service Delivery Increase Satisfaction and Trust? Evidence from a Vignette Experiment." International Journal of Public Administration 38 (9): 642-653. doi:10.1080/01900692.2014.952825.

Fledderus, J., T. Brandsen, and M. Honingh. 2014. "Restoring Trust through the Co-production of Public Services: A Theoretical Elaboration." Public Management Review 16 (3): 424-443. doi:10.1080/14719037.2013.848920.

Gok, M. S., and B. Sezen. 2013. "Analyzing the Ambiguous Relationship between Efficiency, Quality and Patient Satisfaction in Healthcare Services: The Case of Public Hospitals in Turkey." Health Policy 111 (3): 290-300. doi:10.1016/j.healthpol.2013.05.010.

Gustafsson, A., M. D. Johnson, and I. Roos. 2005. "The Effects of Customer Satisfaction, Relationship Commitment Dimensions, and Triggers on Customer Retention.” Journal of Marketing 69: 210-218. doi:10.1509/jmkg.2005.69.4.210.

Hair, J., C. L. Hollingsworth, A. B. Randolph, and A. Y. L. Chong. 2017. "An Updated and Expanded Assessment of PLS-SEM in Information Systems Research.” Industrial Management \& Data Systems 117 (3): 442-458. doi:10.1108/imds-04-2016-0130.

Hartley, J., J. Alford, E. Knies, and S. Douglas. 2017. “Towards an Empirical Research Agenda for Public Value Theory." Public Management Review 19 (5): 670-685. doi:10.1080/ 14719037.2016.1192166.

Heskett, J. L., T. O. Jones, G. W. Loveman, W. E. Sasser, and L. A. Schlesinger. 1994. "Putting the Service-profit Chain to Work." Harvard Business Review 72 (2): 164-174.

Jaspers, S., and T. Steen. 2019. "Realizing Public Values: Enhancement or Obstruction? Exploring Value Tensions and Coping Strategies in the Co-production of Social Care." Public Management Review 21 (4): 606-627. doi:10.1080/14719037.2018.1508608.

Kreutzer, K., and U. Jäger. 2011. "Volunteering versus Managerialism: Conflict over Organizational Identity in Voluntary Associations." Nonprofit and Voluntary Sector Quarterly 40 (4): 634-661. doi:10.1177/0899764010369386.

Kristof, A. L. 1996. "Person-organization Fit: An Integrative Review of Its Conceptualizations, Measurement, and Implications." Personnel Psychology 49 (1): 1-49. doi:10.1111/j.17446570.1996.tb01790.x. 
Kristof Brown, A. L., R. Zimmerman, and E. Johnson. 2005. "Consequences of Individuals' Fit at Work: A Meta-analysis of Person-job, Person-organization, Person-group, and Person-supervisor Fit.” Personnel Psychology 58: 281-342. doi:10.1111/j.1744-6570.2005.00672.x.

Lavasseur, K. 2018. "Co-producing Accountability? Drawing Conclusions from Non-profit Child Care Services in Manitoba." Canadian Public Administration 61 (1): 26-44. doi:10.1111/capa.12252.

Leviten-Reid, C. 2012. "Organizational Form, Parental Involvement, and Quality of Care in Child Day-care Centers." Nonprofit and Voluntary Sector Quarterly 41 (1): 36-57. doi:10.1177/ 0899764010388846.

Loeffler, E., and T. Bovaird. 2016. "User and Community Co-production of Public Services: What Does the Evidence Tell Us?” International Journal of Public Administration 39 (13): 1006-1019. doi:10.1080/01900692.2016.1250559.

Miller, J. L. 2002. "The Board as a Monitor of Organizational Activity: The Applicability of Agency Theory to Nonprofit Boards." Nonprofit Management and Leadership 12 (4): 429-450. doi:10.1002/ nml.12407.

Musso, J. A., M. M. Young, and M. Thom. 2019. "Volunteerism as Co-production in Public Service Management: Application to Public Safety." Public Management Review 21 (4): 473-494.

Nabatchi, T., A. Sancino, and M. Sicilia. 2017. "Varieties of Participation in Public Services: The Who, When, and What of Coproduction." Public Administration Review 77 (5): 766-776. doi:10.1111/ puar.12765.

Nabatchi, T., T. Steen, M. Sicilia, and D. Brand. 2016. "Understanding the Diversity of Coproduction: Introduction to the IJPA Special Issue." International Journal of Public Administration 39 (13): 1001-1005. doi:10.1080/01900692.2016.1177836.

Oliver, R. L., and W. S. DeSarbo. 1988. "Response Determinants in Satisfaction Judgments." Journal of Consumer Research 14 (4): 495-507. doi:10.1086/209131.

Osborne, S. P., K. Strokosch, and Z. Radnor. 2018. "Co-production and the Co-creation of Value in Public Services." In Co-production and Co-creation: Engaging Citizens in Public Services, edited by T. Brandsen, T. Steen, and B. Verschuere, 18-26. Abingdon: Routledge. doi:10.4324/ 9781315204956-3.

Osborne, S. P. 2018. "From Public Service-dominant Logic to Public Service Logic: Are Public Service Organizations Capable of Co-production and Value Co-creation?" Public Management Review 20 (2): 225-231. doi:10.1080/14719037.2017.1350461.

Osborne, S. P., and K. Strokosch. 2013. "It Takes Two to Tango? Understanding the Co-production of Public Services by Integrating the Services Management and Public Administration Perspectives." British Journal of Management 24: S31-S47. doi:10.1111/1467-8551.12010.

Osborne, S. P., Z. Radnor, and G. Nasi. 2013. "A New Theory for Public Service Management? toward A (public) Service-dominant Approach." American Review of Public Administration 43 (2): 135-158. doi:10.1177/0275074012466935.

Osborne, S. P., Z. Radnor, T. Kinder, and I. Vidal. 2015. "The SERVICE Framework: A PublicSERVICE-dominant Approach to Sustainable Public Services." British Journal of Management 26 (3): 424-438. doi:10.1111/1467-8551.12094.

Pestoff, V. 2009. “Towards a Paradigm of Democratic Participation: Citizen Participation and Coproduction of Personal Social Services in Sweden." Annals of Public and Cooperative Economics 80 (2): 197-224. doi:10.1111/j.1467-8292.2009.00384.x.

Pestoff, V. 2012. "Co-production and Third Sector Social Services in Europe: Some Concepts and Evidence." Voluntas 23 (4): 1102-1118. doi:10.1007/s11266-012-9308-7.

Pestoff, V. 2014. "Collective Action and the Sustainability of Co-production." Public Management Review 16 (3): 383-401. doi:10.1080/14719037.2013.841460.

Pestoff, V., S. P. Osborne, and T. Brandsen. 2006. "Patterns of Co-production in Public Services: Some Concluding Thoughts.” Public Management Review 8 (4): 591-595. doi:10.1080/ 14719030601022999 .

Poocharoen, O. O., and B. Ting. 2015. "Collaboration, Co-production, Networks: Convergence of Theories.” Public Management Review 17 (4): 587-614. doi:10.1080/14719037.2013.866479.

Prentice, C. R. 2015. "Why so Many Measures of Nonprofit Financial Performance? Analyzing and Improving the Use of Financial Measures in Nonprofit Research." Nonprofit and Voluntary Sector Quarterly 45 (4): 715-740. doi:10.1177/0899764015595722. 
Risman, K. L., R. J. Erickson, and J. M. Diefendorff. 2016. "The Impact of Person-organization Fit on Nurse Job Satisfaction and Patient Care Quality." Applied Nursing Research 31: 121-125. doi:10.1016/j.apnr.2016.01.007.

Schober, P. S., and C. K. Spiess. 2015. "Local Day-care Quality and Maternal Employment: Evidence from East and West Germany.” Journal of Marriage and Family 77 (3): 712-729. doi:10.1111/ jomf.12180.

Shay, L. A., and J. E. Lafata. 2015. "Where Is the Evidence? A Systematic Review of Shared Decision Making and Patient Outcomes." Medical Decision Making 35 (1): 114-131. doi:10.1177/ 0272989x14551638.

Smith, L. J., and M. L. Friedman. 1994. "Measuring Satisfaction with Services When the Customer Is Not the Consumer: The Child Care Service Example." Journal of Nonprofit \& Public Sector Marketing 2 (1): 9-28. doi:10.1300/j054v02n01_03.

Surva, L., P. Tõnurist, and V. Lember. 2016. "Co-production in a Network Setting: Providing an Alternative to the National Probation Service." International Journal of Public Administration 39 (13): 1031-1043. doi:10.1080/01900692.2016.1193752.

Tepeci, M., and A. B. Bartlett. 2002. "The Hospitality Industry Culture Profile: A Measure of Individual Values, Organizational Culture, and Person-organization Fit as Predictors of Job Satisfaction and Behavioral Intentions." International Journal of Hospitality Management 21 (2): 151-170. doi:10.1016/s0278-4319(01)00035-4.

Vamstad, J. 2012. "Co-production and Service Quality: The Case of Cooperative Childcare in Sweden." Voluntas 23 (4): 1173-1188. doi:10.1007/s11266-012-9312-y.

Van Puyvelde, S., R. Caers, C. Du Bois, and M. Jegers. 2012. "The Governance of Nonprofit Organizations: Integrating Agency Theory with Stakeholder and Stewardship Theories." Nonprofit and Voluntary Sector Quarterly 41 (3): 431-451. doi:10.1177/0899764011409757.

Vargo, S. L., and R. F. Lusch. 2008. "Service-dominant Logic: Continuing the Evolution." Journal of the Academy of Marketing Science 36 (1): 1-10. doi:10.1007/s11747-007-0069-6.

Verschuere, B., T. Brandsen, and V. Pestoff. 2012. "Co-production: The State of the Art in Research and the Future Agenda." Voluntas 23 (4): 1083-1101. doi:10.1007/s11266-012-9307-8.

Vidal, I. 2006. "Reflections on the Market, Networking and Trust." Public Management Review 8 (4): 583-589. doi:10.1080/14719030601022973.

Voorberg, W. H., V. J. Bekkers, and L. G. Tummers. 2015. “A Systematic Review of Co-creation and Co-production: Embarking on the Social Innovation Journey.” Public Management Review 17 (9): 1333-1357. doi:10.1080/14719037.2014.930505.

Wicker, P., and C. Breuer. 2011. "Scarcity of Resources in German Non-profit Sport Clubs." Sport Management Review 14 (2): 188-201. doi:10.1016/j.smr.2010.09.001.

Williams, B. N., S. C. Kang, and J. Johnson. 2016. "(co)-contamination as the Dark Side of Co-production: Public Value Failures in Co-production Processes." Public Management Review 18 (5): 692-717. doi:10.1080/14719037.2015.1111660.

Yaniv, E., and F. Farkas. 2005. "The Impact of Person-organization Fit on the Corporate Brand Perception of Employees and of Customers." Journal of Change Management 5 (4): 447-461. doi:10.1080/14697010500372600. 


\section{Appendix A. Question Items}

Economic Co-Production:

- ... volunteering as a cleaning person.

- .... as a craftsman.

- ... as an accounting clerk.

- ... donation of toys.

- ... monetary donations.

- ... helping with the care of the children.

Social Co-Production:

- ... helping with the planning and holding of celebrations (e.g., Christmas party or Saint Martin's move).

- ... donating, for example, cakes and drinks and money to the organization and the holding of events.

- ... helping to organize and conduct open house days and other events.

Political Co-Production:

- Parents in our day-care centre can advise in meetings with the sponsor/management and can directly influence decisions.

- ... without being able to influence the decisions directly.

- The sponsor/management of the day-care actively consults the parents to find out what their wishes and needs are.

- Parents can send in written suggestions for improvement, and the sponsor/management will consider these suggestions.

- ... always express themselves on important issues and issues in informal conversations (e.g., while picking up children), and these comments are considered by the institution/management.

Level of Information:

- I am always well informed about what is going on in the day-care.

- The day-care always gives me the information that is important to me.

- Before changes or important decisions are made, parents are always well-informed.

Person-Organization Fit

- My values and goals are similar to the values and goals of my child's day-care.

- I cannot get used to the organizational culture of the day-care. (-)

- I feel a sense of belonging to this institution.

- The things that the day-care stands for are also important to me as a parent.

Structural Quality:

- How satisfied are you with the facility's buildings?

- ... furniture and movables?

- ... rooms for playing and learning?

- ... rooms for sleeping and relaxing?

- ... possibilities to play and for sports?

- ... equipment with books and other media?

Satisfaction:

- How satisfied are you with the day-care of your child?

- To what extent does your child's day-care meet your expectations?

- How close is the day-care of your child to the performance or quality of an ideal day-care facility? 


\section{Appendix B. Significant Effects of the Covariates on the Model Components}

\begin{tabular}{clrc}
\hline & & Path & P Values \\
\hline Effects of Parent & 31-40 years $\rightarrow$ Quality & 0.14 & 0.01 \\
Characteristics & 41 years or older $\rightarrow$ Quality & 0.12 & 0.03 \\
& Collage education $\rightarrow$ Satisfaction & & \\
& East Germany $\rightarrow$ Information & 0.06 & 0.01 \\
& East Germany $\rightarrow$ Quality & -0.06 & 0.03 \\
& High school diploma $\rightarrow$ Satisfaction & -0.12 & 0.00 \\
& Non-denominational state $\rightarrow$ Quality & -0.09 & 0.00 \\
& Male $\rightarrow$ P-O Fit & 0.07 & 0.04 \\
& Parents council membership $\rightarrow$ P-O Fit & 0.07 & 0.01 \\
Effects of Facility & Parent initiative $\rightarrow$ Information & -0.09 & 0.02 \\
Characteristics & 0.05 & 0.08 \\
& Religious non-profit status $\rightarrow$ Satisfaction & 0.28 & 0.00 \\
& Migration background $(<10 \%) \rightarrow$ Quality & 0.16 & 0.00 \\
& Migration background $(<10 \%) \rightarrow$ Satisfaction & 0.33 & 0.00 \\
& Satisfaction with teacher-child ratio $\rightarrow$ Information & 0.14 & 0.00 \\
& Satisfaction with teacher-child ratio $\rightarrow$ Person-organization Fit & 0.07 & 0.03 \\
& Satisfaction with teacher-child ratio $\rightarrow$ Quality & 0.06 & 0.04 \\
\hline
\end{tabular}

Notes. Due to space limitations, the figure only reports the significant effects. Satisfaction with the teacher-child ratio is operationalized as a 7-point Likert scale. All other variables are binominal or multi-nominal variables and are operationalized as dummy variables. 